\title{
Unilateral lung transplantation using right and left upper lobes: An experimental study
}

\author{
Hitoshi Nishikawa, MD, Takahiro Oto, MD, PhD, Shinji Otani, MD, PhD, Masaaki Harada, MD, \\ Norichika Iga, MD, Kentaroh Miyoshi, MD, PhD, and Shinichiro Miyoshi, MD, PhD
}

Objective: The shortage of organ donors is a serious problem in Japan. The right and left upper lobes of rejected extended-criteria lungs have the potential to be used for downsized lung transplantation; however, the 2 upper lobes are too small for a size-matched recipient. The present study investigated the feasibility of unilateral transplantation using the right and left upper lobes.

\begin{abstract}
Methods: After harvesting the heart-lung block from donor swine, a left lung graft was created using the right and left upper lobes and transplanted into the left thoracic space of the recipient swine (group A, n =5). We then evaluated graft function for 6 hours and compared these results with those of a control group (group B, $n=5$ ), in which orthotopic left lung transplantation had been performed.
\end{abstract}

Results: The mean partial pressure of oxygen in the arterial blood gas after reperfusion was $507 \mathrm{~mm} \mathrm{Hg}$ in group $\mathrm{A}$ and $463 \mathrm{~mm} \mathrm{Hg}$ in group B $(P=.2)$. The mean pulmonary arterial pressure was $30.3 \mathrm{~mm} \mathrm{Hg}$ in group A and $27.5 \mathrm{~mm} \mathrm{Hg}$ in group $\mathrm{B}(P=.4)$. The mean airway pressure was $6.4 \mathrm{~mm} \mathrm{Hg}$ in group A and $6.2 \mathrm{~mm} \mathrm{Hg}$ in group $\mathrm{B}(P=.7)$.

Conclusions: Our results suggest that unilateral left lung transplantation using the right and left upper lobes is technically and functionally feasible for size-matched recipients. In addition, this technique enables the use of rejected lungs if the upper lobes are still intact. (J Thorac Cardiovasc Surg 2013;146:1534-7)

Donor shortage is a significant limiting factor for lung transplantation in Japan. Of 601 lung transplant candidates from 1998 to 2012, only 169 underwent lung transplantation; 242 died while on the waiting list. The usage of extended-criteria lungs is quite important; therefore, $63 \%$ of donor offers have been accepted for lung transplantation in Japan.

Both lower lobes of extended-criteria lungs will often be collapsed or infected. However, both the upper lobes of these lungs might still be usable for transplantation. ${ }^{2}$ Aigner and colleauges ${ }^{3,4}$ reported successful use of the cutdown lobes of marginal donors for downsized lung transplantation. The 2 upper lobes are usually too small for size-matched recipients; however, if unilateral lung transplantation using the right and left donor upper lobes becomes feasible, they could be used for size-matched recipients. The aim of the present study was to investigate the feasibility of using the right and left donor upper lobes for unilateral lung transplantation in a recipient.

From the Department of General Thoracic Surgery, Okayama University Graduate School of Medicine, Okayama, Japan.

Disclosures: Authors have nothing to disclose with regard to commercial support.

Received for publication May 12, 2013; revisions received July 11, 2013; accepted for publication Aug 16, 2013; available ahead of print Sept 30, 2013.

Address for reprints: Takahiro Oto, MD, PhD, Department of General Thoracic Surgery, Okayama University Graduate School of Medicine, 2-5-1, Shikata-cho,

Kita-ku, Okayama 700-8558, Japan (E-mail: oto@md.okayama-u.ac.jp).

$0022-5223 / \$ 36.00$

Copyright (c) 2013 by The American Association for Thoracic Surgery

http://dx.doi.org/10.1016/j.jtcvs.2013.08.042

\section{METHODS}

The scheme of this experiment is shown in Figure 1. The orifice of the right upper bronchus (Figure 2, A) and right upper pulmonary vein (PV) (Figure 2, B) were reconstructed by suturing the right and left stumps side to side in accordance with the method described by Oto and colleagues. ${ }^{5}$ Thus, the stump of the right upper pulmonary artery (PA) came close to the stump of the left basal PA, which made an in-series connection possible (Figure 2, C).

\section{Donor Operation}

The details of monitoring and anesthesia of the pigs have been previously described. ${ }^{6}$ In brief, ketamine chloride and atropine sulfate were injected intramuscularly as premedication. Ventilation was performed through an endotracheal tube, and the fraction of inspired oxygen was established at 1.0. Desensitization and optimal paralysis were fully maintained using halothane and vecuronium bromide. The airway pressure (AWP), blood pressure, pulmonary arterial pressure (PAP), central venous pressure, arterial blood gases, PA blood gases, and cardiac output were measured.

After a median sternotomy, $200 \mathrm{U} / \mathrm{kg}$ of heparin was injected intravenously. Ligation of the main PA marked the onset of the graft ischemic time. Flushing of both lungs was performed using $1000 \mathrm{~mL}$ of a low-potassium-dextrin-glucose solution, ${ }^{7}$ and the heart-lung block was extracted.

\section{Study Group}

In group A, the pigs received unilateral lung transplantation using the right and left donor upper lobes $(n=5)$. Both upper lobes were separated from the heart-lung block, and a wide anastomosing orifice of the right and left bronchi and PVs was created using side-to-side running suture (Figure 2, $A$ and $B$ ). An end-to-end anastomosis of the right upper PA to the left basal PA (Figure 2, $C$ ) was also created. Thus, a double upper lobe graft was created (Figure 3).

In group B, the control group of pigs underwent orthotopic left lung transplantation $(n=5)$. The heart-lung block was extracted, and a left 


\section{Abbreviations and Acronyms}

AWP $=$ airway pressure

PA = pulmonary artery

PAP $=$ pulmonary arterial pressure

$\mathrm{PV}=$ pulmonary vein

PV cuff was created from the left atrium. The left PA and left bronchus were cut at each bifurcation.

\section{Recipient Operation}

The pig was placed in the right lateral position, and a fifth intercostal thoracotomy was performed. The left PV, left main PA, and left main bronchus were separated, and the left lung was extracted. Heparin (200 U/kg) was administered intravenously. The pulmonary structures were anastomosed in the following order: bronchus (Figure 2, A), PA (Figure 2, C), and PV (Figure 2, B). The bronchus was anastomosed using a running 4-0 Prolene suture, and the PA and PV were anastomosed using running sutures of 6-0 Prolene.

The clamps were released from the PV, PA, and bronchus. The pig was returned to the supine position. The arterial blood gases, PA blood gases, cardiac output, AWP, PAP, central venous pressure, and left atrial pressure were measured at $0,30,60,120$, and 180 minutes after reperfusion. After the measurement at 180 minutes, the graft was pushed into the thorax, and the chest was closed; subsequently, measurements at 240 through 360 minutes were obtained. The right main PA was intermittently clamped using a tourniquet for 5 minutes before each measurement. Pulmonary arteriography was performed to check for stenosis or occlusion of the anastomoses (Figure 4). The following 3 measured parameters were assigned to evaluate graft function: partial pressure of oxygen in arterial

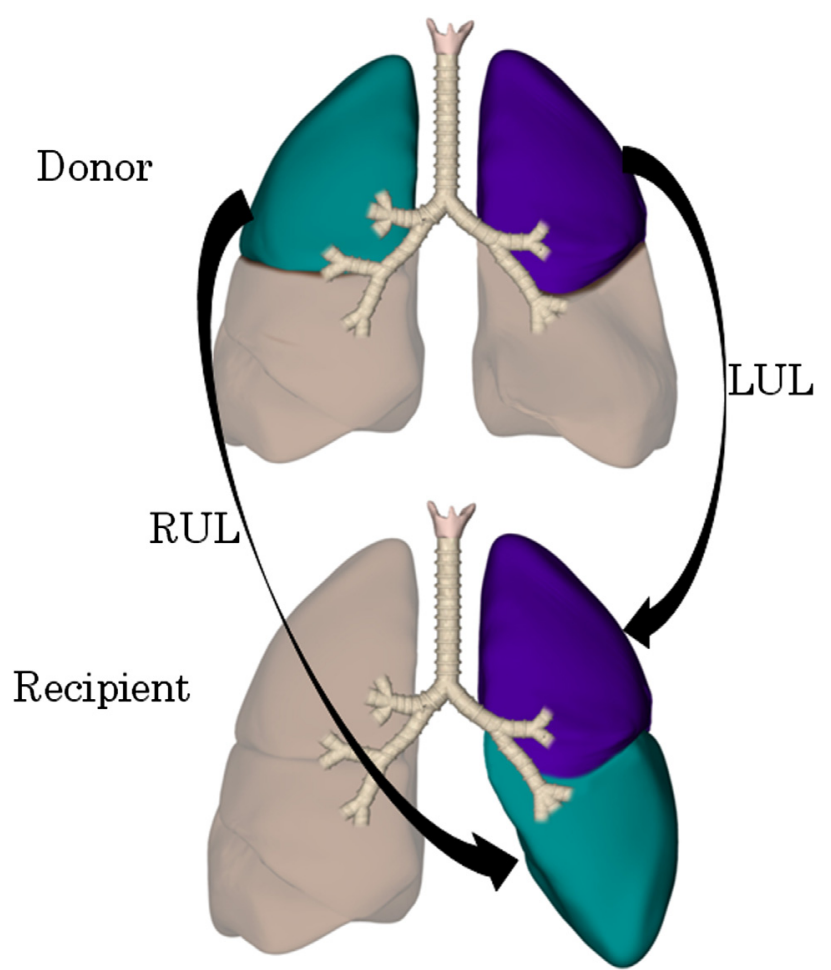

FIGURE 1. Experimental design, group A. RUL, Right upper lobe; $L U L$, left upper lobe.
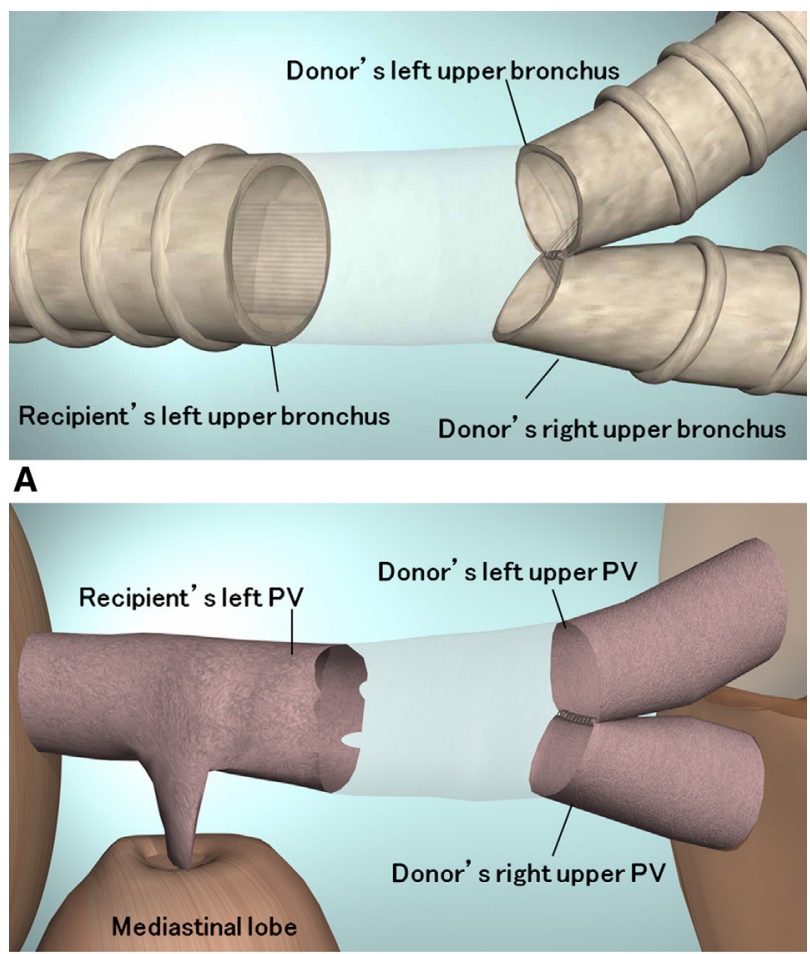

B

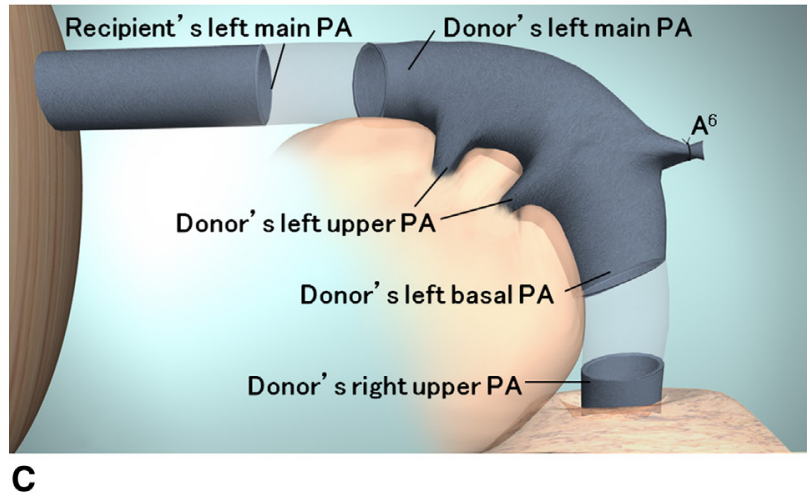

FIGURE 2. Method of anastomosis. A, bronchus; B, pulmonary vein $(P V)$; and C, pulmonary artery $(P A)$.

blood gases for oxygenation or gas exchange; PAP for problems in vessel anastomosis and influence of the small pulmonary vascular beds; and AWP for decreased lung compliance due to congestion of the graft, problems with the bronchial anastomosis, or secretions.

The details of the preoperative characteristics are listed in Table 1. No significant differences were found between the 2 groups $(P>.1)$.

\section{Statistical Analysis}

All results are expressed as the mean \pm standard error of the mean. The Mann-Whitney $U$ test was used to verify the differences in values for the preoperative characteristics. Two-way repeated measurement analysis of variance was used for comparison of serial values. Differences were accepted as significant if $P<.05$.

\section{Animal Care}

All the pigs received humane care in compliance with the European Convention on Animal Care and the Principles of Laboratory Animal 


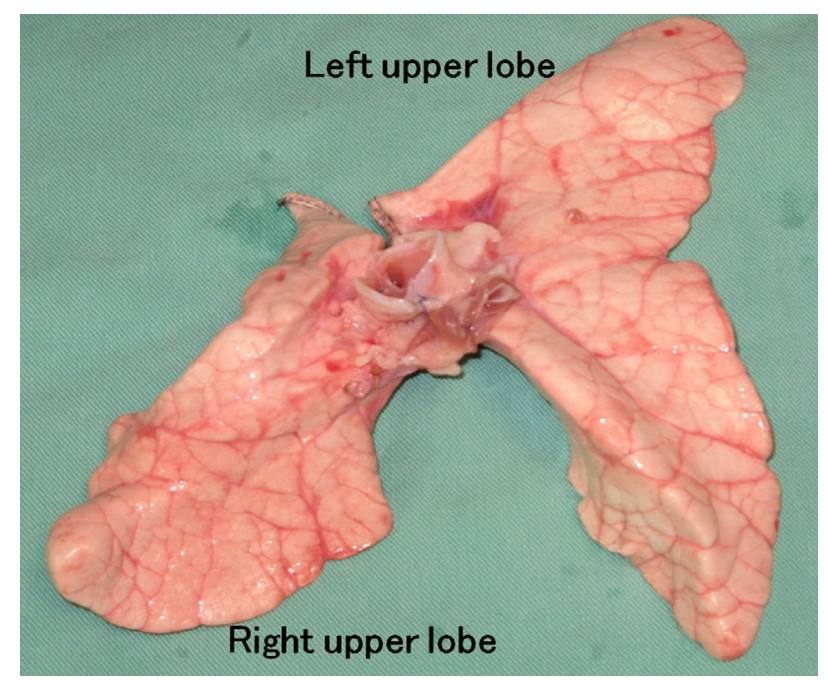

FIGURE 3. Bilobar graft.

Care, formulated by the National Society for Medical Research, and the Guide for the Care and Use of Laboratory Animals, prepared by the Institute of Laboratory Animal Resources and published by the National Institutes of Health (Bethesda, Md; National Institutes of Health publication no. 86-23, revised 1996).

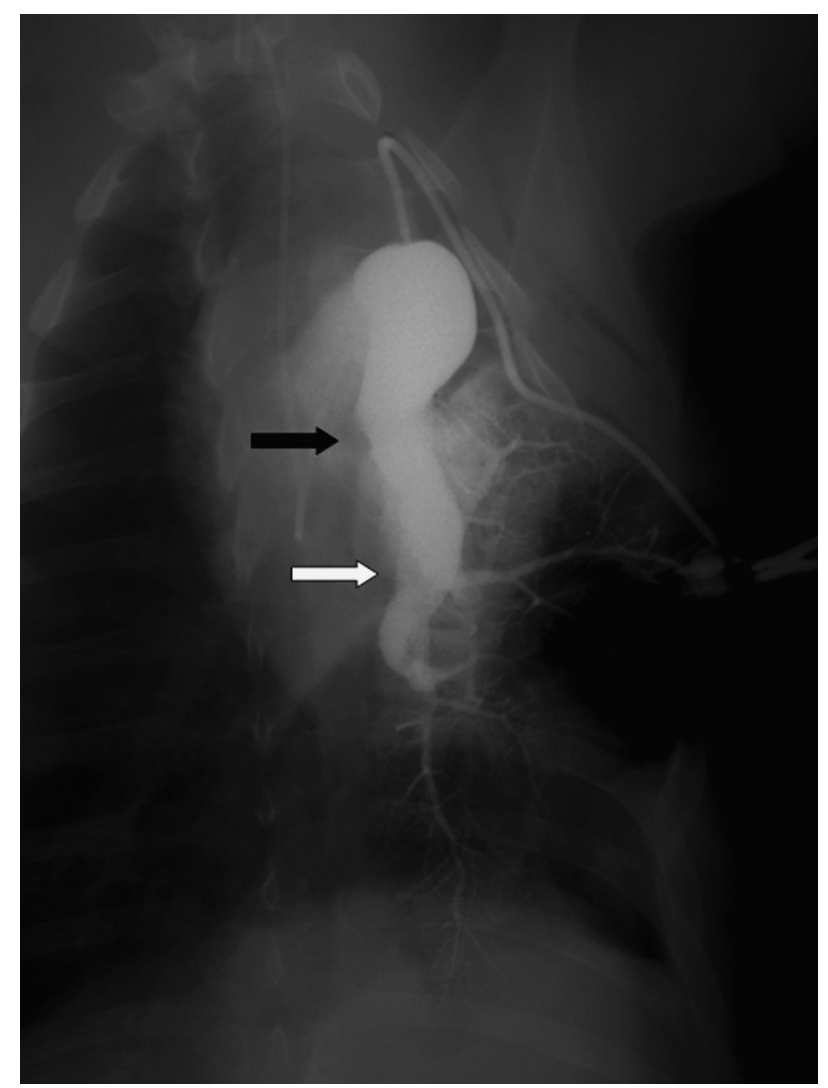

FIGURE 4. Pulmonary arteriography of the bilobar graft after reperfusion. Anastomotic portions of the left main pulmonary artery (PA) to the left upper PA (black arrow) and the left basal PA to the right upper PA (white arrow) showed good patency.
TABLE 1. Preoperative characteristic of recipients

\begin{tabular}{lcc}
\hline \multicolumn{1}{c}{ Characteristic } & $\begin{array}{c}\text { Group A } \\
\text { (bilobar; } \mathbf{n}=\mathbf{5})\end{array}$ & $\begin{array}{c}\text { Group B } \\
\text { (control; n }=\mathbf{5} \text { ) }\end{array}$ \\
\hline Donor weight $(\mathrm{kg})$ & $26.6 \pm 0.87$ & $28.6 \pm 0.86$ \\
$\mathrm{PaO}_{2}$ of donor $(\mathrm{mm} \mathrm{Hg})$ & $535 \pm 34$ & $493 \pm 36$ \\
Recipient weight $(\mathrm{kg})$ & $26.8 \pm 0.73$ & $27.7 \pm 0.81$ \\
Ischemic time $(\mathrm{min})$ & $326 \pm 10$ & $259 \pm 28$ \\
$\mathrm{CO}(\mathrm{L} / \mathrm{min})$ & $4.32 \pm 0.37$ & $4.4 \pm 0.55$ \\
$\mathrm{PAP}(\mathrm{mm} \mathrm{Hg})$ & $24 \pm 2.92$ & $31.2 \pm 1.16$ \\
$\mathrm{PaO}_{2}(\mathrm{~mm} \mathrm{Hg})$ & $529 \pm 29$ & $550 \pm 18$ \\
\hline
\end{tabular}

Data presented as mean \pm standard error of mean. $\mathrm{PaO}_{2}$, Partial pressure of oxygen in arterial blood gases; $C O$, cardiac output; $P A P$, pulmonary arterial pressure.

\section{RESULTS}

At 6 hours after reperfusion, the mean values for groups $\mathrm{A}$ and $\mathrm{B}$, respectively, were as follows: partial pressure of oxygen in arterial blood gases, 507 and $463 \mathrm{~mm} \mathrm{Hg}$ $(P=.2$; Figure $5, A)$; PAP, 30.3 and $27.5 \mathrm{~mm} \mathrm{Hg}(P=.4$; Figure $5, B)$; and AWP, 6.4 and $6.2 \mathrm{~mm} \mathrm{Hg}(P=.7$; Figure $5, B)$. Thus, the noninferiority of this technique was confirmed.

\section{DISCUSSION}

Because of a donor shortage, mortality is high among the wait-listed lung transplant candidates. Extended-criteria lungs have been used to overcome this problem. Although
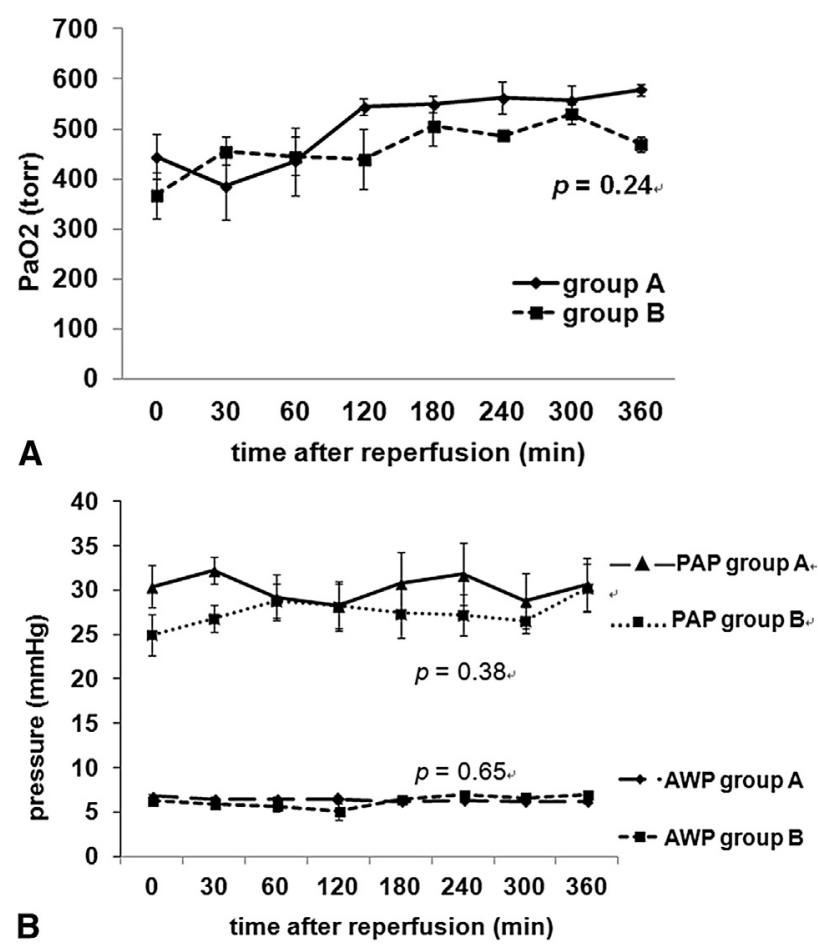

FIGURE 5. A, Sequential value of oxygen partial pressure in arterial blood gas $\left(\mathrm{PaO}_{2}\right)$. No significant difference was seen in the blood gas analysis values between groups A and B. B, Sequential value of pulmonary arterial pressure $(P A P)$ and airway pressure $(A W P)$. No significant differences were seen in the PAP or AWP between groups A and B. 
both lower lobes of extended-criteria lungs will often be collapsed or infected, the upper lobes could still be usable for lung transplantation. Many transplant teams would still prefer to perform bilateral, full lung transplantation in a low-risk recipient with the hope that the damaged lower lobes will recover during the first days after transplantation. However, when the damage of bilateral lower lobes has been judged to be irreversible, all lobes, including the healthy upper lobes, would be rejected at a not negligible frequency. The aim of the present study was to determine the efficient utility of such upper lobes.

When 2 upper lobes are used for bilateral lung transplant, the lung volume could be enough for an undersized recipient. However, it might be too small for size-matched recipients. In contrast, the volume of the 2 upper lobes might be sufficient for a size-matched recipient if these lobes were transplanted unilaterally into the thoracic cavity. For adults, unilateral lung transplantation is less invasive than bilateral transplantation, and the residual contralateral lung is still functional. Therefore, unilateral lung transplantation using the right and left donor upper lobes might be feasible and could be used for size-matched recipients.

It should be noted that unilateral lung transplantation using the right and left donor upper lobes has potential disadvantages. One limitation of the present study was that swine lungs were used instead of human lungs. Some anatomic differences exist between swine and human lungs, including the shape of the rib cage, the orifice portion of the right superior bronchus, and the existence of the mediastinal lobe in pigs. Another limitation was that the present study was an acute-phase experiment. The technique might have a greater risk of bronchial anastomotic complications, infection, and ventilation-perfusion mismatch in the long term. The bilobar grafts unexpectedly fit into a good position in the left thoracic space without torsion or kinking in our experiment. However, the lobes were placed in a nonphysiologic manner; therefore, atelectasis and bronchial or vascular distortion could occur. Dead space could lead to persistent pneumothorax or thoracic empyema. ${ }^{8}$ Additional examination investigating the shape, size, and geometry of the lobes using human rejected lungs is required to clarify these points.

\section{CONCLUSIONS}

Our results have suggested the feasibility of unilateral lung transplantation using right and left donor upper lobes in pigs. This technique could enable usage of the intact upper lobes of otherwise rejected lungs for transplantation.

We heartily thank Mr Tetsuo Kawakami and Mr Mitsugu Honda for their expert technical support.

\section{References}

1. Oto T, Okada Y, Bando T, Minami M, Shiraishi T, Nagayasu T, et al. Registry of the Japanese Society of Lung and Heart-Lung Transplantation: the official Japanese lung transplantation report 2012. Gen Thorac Cardiovasc Surg. 2013; 61:208-11

2. Yeung JC, Cypel M, Waddell TK, van Raemdonck D, Keshavjee S. Update on donor assessment, resuscitation, and acceptance criteria, including novel techniques non-heart-beating donor lung retrieval and ex vivo donor lung perfusion. Thorac Surg Clin. 2009;19:261-74.

3. Aigner C, Winkler G, Jaksch P, Ankersmit J, Marta G, Taghavi S, et al. Sizereduced lung transplantation: an advanced operative strategy to alleviate donor organ shortage. Transplant Proc. 2004;36:2801-5

4. Aigner C, Jaksch P, Taghavi S, Wisser W, Marta G, Winkler G, et al. Donor total lung capacity predicts recipient total lung capacity after size-reduced lung transplantation. J Heart Lung Transplant. 2005;24:2098-102.

5. Oto T, Rabinov M, Negri J, Marasco S, Rowland M, Pick A, et al. Techniques of reconstruction for inadequate donor left atrial cuff in lung transplantation. Ann Thorac Surg. 2006;81:1199-204

6. Otani S, Oto T, Kakishita T, Miyoshi K, Hori S, Yamane M, et al. Early effects of the ex vivo evaluation system on graft function after swine lung transplantation. Eur J Cardiothorac Surg. 2011;40:956-61.

7. Date H, Matsumura A, Manchester JK, Obo H, Lima O, Cooper JM, et al. Evaluation of lung metabolism during successful twenty-four-hour canine lung preservation. J Thorac Cardiovasc Surg. 1993;105:480-91.

8. Backhus LM, Sievers EM, Schenkel FA, Barr ML, Cohen RG, Smith MA, et al Pleural space problems after living lobar transplantation. J Heart Lung Transplant. 2005;24:2086-90. 